\title{
THEORY AND METHODS
}

\section{Defining equity in health}

\section{P Braveman, S Gruskin}

See end of article for authors' affiliations

......................

Correspondence to: Dr P Braveman

Department of Family and Community Medicine, University of California, San Francisco, 500

Parnassus Avenue, MU-3E, San Francisco, California, 94143-0900, USA:

pbrave@itsa.ucsf.edu

Accepted for publication 21 October 2002

\begin{abstract}
Study objective: To propose a definition of health equity to guide operationalisation and measurement, and to discuss the practical importance of clarity in defining this concept.

Design: Conceptual discussion.

Setting, Patients/Participants, and Main results: not applicable.

Conclusions: For the purposes of measurement and operationalisation, equity in health is the absence of systematic disparities in health (or in the major social determinants of health) between groups with different levels of underlying social advantage/disadvantage-that is, wealth, power, or prestige. Inequities in health systematically put groups of people who are already socially disadvantaged (for example, by virtue of being poor, female, and/or members of a disenfranchised racial, ethnic, or religious group) at further disadvantage with respect to their health; health is essential to wellbeing and to overcoming other effects of social disadvantage. Equity is an ethical principle; it also is consonant with and closely related to human rights principles. The proposed definition of equity supports operationalisation of the right to the highest attainable standard of health as indicated by the health status of the most socially advantaged group. Assessing health equity requires comparing health and its social determinants between more and less advantaged social groups. These comparisons are essential to assess whether national and international policies are leading toward or away from greater social justice in health.
\end{abstract}

equ a widely cited 1992 paper on The concepts and principles of equity in health. Whitehead defined health inequities as differences in health that are unnecessary, avoidable, unfair and unjust. ${ }^{1}$ That influential, articulate, and well conceived paper was "...not meant to be a technical document, but ....aimed at raising awareness and stimulating debate in a wide, general audience..." in Europe. ${ }^{1}$ The document succeeded in its stated aim and has been useful in many settings on other continents. Valuable contributions also have been made by other discussions of the concept of equity in health or in health care, or both. ${ }^{2-13}$ Accumulated experience now permits a fresh look at the question of how to define equity in health in a conceptually rigorous fashion that can guide measurement and hence accountability for actions at the policy and programmatic levels. This question is of particular relevance given the growing interest in equity among national and international health organisations. ${ }^{6}{ }^{1011}{ }^{14-32}$ The need for a more precise definition of equity in health also has arisen in the context of a recent debate between researchers at the World Health Organisation ${ }^{33-35}$ and at a number of academic institutions ${ }^{36-38}$; this debate is discussed below (see Do the definitions matter?). This paper is primarily addressed to the research community, proposing a definition of health equity to guide measurement and, hence, accountability; we also discuss the practical importance of clarity in defining this concept, in terms of consequences for both policies and measurement. We are not aware of other literature addressing this issue.

\section{EQUITY MEANS SOCIAL JUSTICE}

Equity means social justice or fairness; it is an ethical concept, grounded in principles of distributive justice. ${ }^{39-42}$ Equity in health can be-and has widely been-defined as the absence of socially unjust or unfair health disparities. ${ }^{16}$ However, because social justice and fairness can be interpreted differently by different people in different settings, a definition is needed that can be operationalised based on measurable criteria.
For the purposes of operationalisation and measurement, equity in health can be defined as the absence of systematic disparities in health (or in the major social determinants of health) between social groups who have different levels of underlying social advantage/disadvantage-that is, different positions in a social hierarchy. Inequities in health systematically put groups of people who are already socially disadvantaged (for example, by virtue of being poor, female, and/or members of a disenfranchised racial, ethnic, or religious group) at further disadvantage with respect to their health; health is essential to wellbeing and to overcoming other effects of social disadvantage.

Health represents both physical and mental wellbeing, not just the absence of disease. ${ }^{43}$ Key social determinants of health include household living conditions, conditions in communities and workplaces, and health care, along with policies and programmes affecting any of these factors. ${ }^{43-50}$ Health care is a social determinant in so far as it is influenced by social policies; we use the term broadly here to refer not only to the receipt/utilisation of health services, but also to the allocation of health care resources, the financing of health care, and the quality of health care services.

Underlying social advantage or disadvantage refers to wealth, power, and/or prestige- - that is, the attributes that define how people are grouped in social hierarchies. Disadvantage also can be thought of as deprivation, ${ }^{5152}$ which can be absolute or relative $^{5354}$; the concept of human poverty developed by the United Nations Development Program reflects severe disadvantage. ${ }^{55}$ Thus, more and less advantaged social groups are groups of people defined by differences that place them at different levels in a social hierarchy. Examples of more and less advantaged social groups include socioeconomic groups (typically defined by measures of income, economic assets, occupational class, and/or educational level), racial/ethnic or religious groups, or groups defined by gender, geography, age, disability, sexual orientation, and other characteristics relevant to the particular setting. This is not an exhaustive list, but social advantage is distributed along these lines virtually everywhere in the world. A health disparity must be systematically 
associated with social advantage, that is, the associations must be significant and frequent or persistent, not just occasional or random. ${ }^{56}$

\section{EQUITY IS NOT THE SAME AS EQUALITY}

The concept of equity is inherently normative-that is, value based ${ }^{137}$; while equality is not necessarily so. ${ }^{1691057}$ Often, the term health inequalities is used as a synonym for health inequities, perhaps because inequity can have an accusatory, judgmental, or morally charged tone. However, it is important to recognise that, strictly speaking, these terms are not synonymous. The concept of health equity focuses attention on the distribution of resources and other processes that drive a particular kind of health inequality - that is, a systematic inequality in health (or in its social determinants) between more and less advantaged social groups, in other words, a health inequality that is unjust or unfair.

Not all health disparities are unfair. ${ }^{26}$ For example, we expect young adults to be healthier than the elderly population. Female newborns tend to have lower birth weights on average than male newborns. Men have prostate problems, while women do not. It would be difficult, however, to argue that any of these health inequalities is unfair. However, differences in nutritional status or immunisation levels between girls and boys, or racial/ethnic differences in the likelihood of receiving appropriate treatment for a heart attack, would be causes for grave concern from an equity perspective.

\section{EQUITY AND HUMAN RIGHTS: EQUAL RIGHTS AND OPPORTUNITIES TO BE HEALTHY}

The concept of equity is an ethical principle; it also is consonant with and closely related to human rights principles. The right to health as set forth in the WHO Constitution ${ }^{43}$ and international human rights treaties is the right to "the highest attainable standard of health." Although this notion has sometimes been criticised by public health practitioners for being vague and difficult to operationalise, accumulating experience suggests its utility. ${ }^{58-63}$ We believe that the highest attainable standard of health can be understood to be reflected by the standard of health enjoyed by the most socially advantaged group within a society. One could argue that, given sufficient resources, the highest attainable standard could be far greater than that currently experienced even by the best off group in a society. The health levels of the most privileged groups in a given society at least reflect levels that clearly are biologically attainable, and minimum standards for what should be possible for everyone in that society within a foreseeable future. The proposed definition of equity in health thus is useful in operationalising the concept of the right to health.

While it is important, as noted above, to be clear about the distinction between health inequalities and health inequities, the concepts of equality and equal rights are none the less central and indispensable. The concept of equality is indispensable for the operationalisation and measurement of health equity and is important for accountability under the human rights framework. Equality can be assessed with respect to specified measurable outcomes, whereas judging whether a process is equitable or not is more open to interpretation. Furthermore, in practical terms, it is generally those who are in positions of power who are likely to be determining at a societal level what is equitable and what is not, with respect to the allocation of resources necessary for health. For example, in some countries where women are particularly disenfranchised, those in power have argued that conditions for women in their countries are not unfair but rather are appropriate given the different capacities and roles of men and women; similar arguments have been used to justify racial/ethnic discrimination. ${ }^{64-66}$ In such contexts, equality is a crucial reference point in attempts to achieve greater equity in health.

Furthermore, the notion of equal opportunities to be healthy is fundamental to the concept of equity in health and closely linked with the concept of equal rights to health. The notion of equal opportunities to be healthy is grounded in the human rights concept of non-discrimination and the responsibility of governments to take the necessary measures to eliminate adverse discrimination-in this case, discrimination in opportunities to be healthy in virtue of belonging to certain social groups. A selective concern for worse off social groups is not discriminatory; it reflects a concern to reduce discrimination and marginalisation. Equal opportunity to be healthy refers to the attainment by all people of the highest possible level of physical and mental wellbeing that biological limitations permit, noting that the consequences of many biological limitations are amenable to modification. For example, the functional limitations associated with many physical handicaps can be markedly changed with basic measures (such as providing wheelchairs, installing protective railings, or providing physical training to increase mobility and strength); similarly, the degree of impairment associated with many psychological and physical conditions is highly related to the degree of social stigmatisation or acceptance of people with those conditions. ${ }^{6768}$

According to human rights principles, all human rights are considered inter-related and indivisible. ${ }^{69} 70$ Thus, the right to health cannot be separated from other rights, including rights to a decent standard of living and education as well as to freedom from discrimination and freedom to participate fully in one's society. Equalising opportunities to be healthy requires addressing the most important social and economic determinants of health, including, as stated earlier, not only health care but also living conditions in households and communities, working conditions, and policies that affect any of these factors. Concern for equal opportunities to be healthy is the basis for including within the definition of equity in health the absence of systematic social disparities not only in health status but in its key social determinants.

\section{EASE OF AVOIDABILITY SHOULD NOT BE A CRITERION FOR INEQUITY}

The 1990 Concepts and principles paper ${ }^{1}$ defined inequity in health as inequalities in health that are unjust, unfair and avoidable. That definition has been very helpful in giving the abstract notion of equity meaning in terms that most people understand and recognise as a widely shared social value. However, we recommend that avoidability not be used as a criterion to define equity in health, for two reasons. Firstly, including this criterion is unnecessary, because unjust and unfair imply avoidability. Secondly, certain health inequities may be extremely challenging to tackle because they require fundamental changes in underlying social and economic structures; one would not want the ease of avoidability to be a measure of the degree of inequity. Furthermore, using avoidability as a criterion introduces but begs the question: avoidable by whom? Is a given health disparity that adversely affects already disadvantaged groups in a poor country considered to be avoidable by the groups adversely affected, by their community, by government—and at what level—and/or by the international community?

Thus, in defining equity in health, avoidability should only be invoked in so far as injustice and unfairness imply avoidability. The degree to which an inequitable health disparity is avoidable does, however, have important practical implications for efforts to achieve greater equity, in that it will generally be easier to mobilise public opinion and policies to address disparities that are more clearly and easily recognisable as avoidable, particularly those that can be achieved more quickly, at lower cost and with less challenge to underlying 
social and economic structures. This is a pragmatic consideration and should not be considered a fundamental component of the definition of equity.

\section{CAUSAL ASSUMPTIONS}

According to the definition of equity proposed here, a health disparity is inequitable if it is systematically associated with social disadvantage in a way that puts an already disadvantaged social group at further disadvantage. In addition, it must be reasonable based on current scientific knowledge to believe that social determinants could play an important part in that disparity at one or more points along the causal pathways leading to it; that is, that at least one factor associated with social disadvantage is causally connected with at least one factor associated (directly or indirectly) with the specified health condition or determinant. This does not, however, require definitive understanding of the most proximate-that is, immediate cause ( $\mathrm{s}$ ), the causes most amenable to intervention, or the entire causal pathway(s) explaining a health disparity between social groups. The causes of health disparities between more and less advantaged groups are likely to be complex and multifactorial, and may not be clearly or immediately linked to underlying differences in social advantage. A health disparity between more and less advantaged population groups constitutes an inequity not because we know the proximate causes of that disparity and judge them to be unjust, but rather because the disparity is strongly associated with unjust social structures; those structures systematically put disadvantaged groups at generally increased risk of ill health and also generally compound the social and economic consequences of ill health.

Given the complex and multifactorial nature of the causal pathways leading from underlying social determinants to most health disparities, causal assumptions should not be made based on observed associations between particular measures of social advantage and any given health outcome. For example, when a particular health disparity in a society is systematically seen across income groups, the underlying causal differences could be in factors associated with income rather than in income itself; thus, it would be a mistake to assume that efforts focused only on equalising income would necessarily be effective in reducing that particular inequity.

\section{DO THE DEFINITIONS REALLY MATTER?}

In practice, different social, political, economic and cultural contexts, will undoubtedly suggest the need for different ways of defining and explaining equity. However, clarity is required to determine when different definitions represent substantially different paradigms, and the implications of adopting these different paradigms in particular contexts. As noted earlier, people often use the term health inequalities in what may be an effort to avoid the judgmental or moral connotations that may be associated with health inequities. Health inequalities is less cumbersome than social inequalities in health, the latter term also often used as a more succinct way of referring to inequalities in health between more and less advantaged social groups. We believe that using these more concise terms will not be problematic so long as there is clarity as to how they are being used-that is, that both health inequalities and social inequalities in health mean inequalities in health or its social determinants, between more and less advantaged social groups, favouring the already more advantaged groups. When using the more abbreviated expressions, one must be clear that equity, at least as understood here and in the vast majority of the literature, cannot be assessed without comparing how better off and worse off social groups are faring in relation to each other. The importance of clarity regarding these concepts is illustrated by a recent debate.

\section{Key points}

- A definition of equity in health is needed that can guide measurement and hence accountability for the effects of actions.

- Health equity is the absence of systematic disparities in health (or its social determinants) between more and less advantaged social groups.

- Social advantage means wealth, power, and/or prestigethe attributes defining how people are grouped in social hierarchies.

- Health inequities put disadvantaged groups at further disadvantage with respect to health, diminishing opportunities to be healthy.

- Health equity, an ethical concept based on the principle of distributive justice, is also linked to human rights.

The World Health Organisation's (WHO) World Health Report for the year $2000^{71}$ made a welcome argument for the importance of assessing health not only by average levels but also by examining its distribution. However, the report examines the distribution of health by measuring what it refers to as "pure health inequalities," disparities in health between ungrouped individuals, in contrast with examining differences between social groups. ${ }^{33-35}$ The total magnitude of health differences among all individuals is assessed, but there are no comparisons of health among different social groups. Thus, the WHO measure compares the health of healthier people with the health of sicker people within a country, but does not, for example, compare the health of wealthier people with the health of poorer ones, the health of different ethnic groups with each other, or health care for men and women with similar health conditions. Nevertheless, most audiences naturally assume that work on health inequalities is work on health equity.

The measurement of health disparities without respect to how the disparities are distributed socially is not a measure of equity and does not reflect fairness or justice with respect to health. ${ }^{2} 36377273$ If countries or organisations use this WHO measure rather than established measures of health equity (reviewed comprehensively in Mackenbach and Kunst ${ }^{74}$ and Wagstaff $e t a l^{75}$ ), they will be unable to monitor differences in health and health care between the rich and the poor or between more and less privileged racial/ethnic groups or to make appropriate comparisons with respect to gender. Without such comparisons between identifiable social groups, it will not be known who is benefiting most or least from policies affecting health and therefore how best to target interventions or redistribute resources to achieve greater health equity. ${ }^{36}{ }^{37}$ Thus, the choice of definition for equity in health matters because of the implications for the utility of measurement.

\section{CONCLUSION}

Equity in health is an ethical value, inherently normative, grounded in the ethical principle of distributive justice and consonant with human rights principles. Like most concepts, equity in health cannot be directly measured, but we have proposed a definition of equity in health that can be operationalised based on meaningful and measurable criteria. In operational terms, and for the purposes of measurement, equity in health can be defined as the absence of disparities in health (and in its key social determinants) that are systematically associated with social advantage/disadvantage. Health inequities systematically put populations who are already socially disadvantaged (for example, by virtue of being poor, female, or members of a disenfranchised racial, ethnic, or religious group) at further disadvantage with respect to their health.

While equity and equality are distinct, the concept of equality is indispensable in operationalising and measuring health 
equity. Equity in health means equal opportunity to be healthy, for all population groups. Equity in health thus implies that resources are distributed and processes are designed in ways most likely to move toward equalising the health outcomes of disadvantaged social groups with the outcomes of their more advantaged counterparts. This refers to the distribution and design not only of health care resources and programmes, but of all resources, policies, and programmes that play an important part in shaping health, many of which are outside the immediate control of the health sector.

Awareness of the need for greater clarity about the definition of health equity has arisen in the context of a recently proposed approach to the measurement of health inequalities that does not reflect how health is distributed across different social groups. ${ }^{33-37}$ Not all health inequalities necessarily reflect inequity in health, which implies unfair processes in the distribution of resources and other conditions that affect health. Assessing health equity requires comparing health and its social determinants among more and less advantaged social groups. Without that information, we will be unable to assess whether policies and programmes are leading toward or away from greater social justice in health.

\section{ACKNOWLEDGEMENTS}

The authors are grateful for valuable critical comments and editing by Dr Susan Egerter and for detailed and thoughtful comments by an anonymous reviewer.

\section{Authors' affiliations}

P Braveman, Department of Family and Community Medicine, University of California, San Francisco, USA

S Gruskin, International Health and Human Rights Program, Francois Xavier Bagnoud Center for Health and Human Rights, Harvard University School of Public Health, USA

\section{REFERENCES}

1 Whitehead $\mathbf{M}$. The concepts and principles of equity in health. Int J Health Serv 1992;22:429-445. (first published with the same title from: Copenhagen: World Health Organisation Regional Office for Europe, 1990 (EUR/ICP/RPD 414).)

2 Anand S. The concern for equity in health. J Epidemiol Community Health 2002;56:485-7.

3 Culyer AJ. The promise of a reformed NHS: an economist's angle. BM 1991;302:1253-6.

4 Culyer AJ, Wagstaff A. Equity and equality in health and health care. $J$ Health Econ 1993;12:431-57

5 Daniels N. Just health care. New York: Cambridge University Press, 1985

6 Evans T, Whitehead M, Diderichsen F, et al, eds. Challenging inequities in health: from ethics to action. New York: Oxford University Press, 2001

7 Wagstaff A, van Doorslaer E, Paci P. Horizontal equity in the delivery of health care. J Health Econ 1991;10:251-6.

8 Wagstaff A, van Doorslaer E. Equity in the finance of health care: some international comparisions. J Health Econ 1992;11:361-87.

9 Chang W-C. The meaning and goals of equity in health. J Epidemiol Community Health 2002;56:488-91.

10 Equinet. The network on equity in health in Southern Africa. (http://www.equinetafrica.org).

11 Global Equity Gauge Alliance. (http://www.hst.org.za/hlink/ equityint.htm).

12 International Society of Equity in Health. (http://www.iseqh.org/en/ index.htm).

13 UK Health Equity Network. (http://www.ukhen.org.uk).

14 Acheson D, Barker D, Chambers J, et al. The report of the independent inquiry into inequalities in health. London: The Stationery Office, 1998.

15 Birdsall N, Hecht R. Swimming against the tide: strategies for improving equity in health. Human Resources Development and Operations Policy (HROWP 55). Washington, DC: World Bank, 1995

16 Braveman PA, Tarimo E. Social inequalities in health within countries: not only an issue for affluent nations. Soc Sci Med 2002;54:1621-35.

17 Braveman P. Monitoring equity in health: a policy-oriented approach in low- and middle-income countries. Geneva: World Health Organisation (WHO/CHS/HSS/98.1, Equity Initiative Paper No.3), 1998:92.

18 Braveman P. Equity in health and health care: a World Health Organization (WHO) initiative. Geneva: WHO (ARA/96.1), 1996:49.

19 Carr D, Gwatkin D, Fragueiro D, et al. A guide to country level information about equity, poverty, and health available from multi-country research programs. Washington, DC: World Bank, 1999.
20 Deaton A. Inequalities in income and inequalities in health. NBER (National Bureau of Economic Research) Working Paper W7141, May 1999. (http://papers.nber.org/papers/W7141).

21 deKadt E, Tasca R. Promoting equity: a new approach from the health sector. Washington, DC: Pan American Health Organization, 1993:92.

22 United States Department of Health and Human Services. Healthy People 2010: understanding and improving health. Washington, DC: USDHHS, 2000

23 Kaplan GA, Pamuk ER, Lynch JW, et al. Inequality in income and mortality in the United States: analysis of mortality and potential pathways. BM 1996;312:999-1003.

24 Kawachi I, Kennedy BP. The health of nations: why inequality is harmful to your health. New York: The New Press, 2002

25 Kunst AE, Groenhof F, Mackenbach JP, et al. Occupational class and cause specific mortality in middle aged men in 11 European countries: comparison of population-based studies. BM 1998;316:1636-42.

26 Leon DA, Chenet L, Shkolnikov VM, et al. Huge variation in Russian mortality rates 1984-94: artefact, alcohol, or what? Lancet 1997;350:383-8

27 Macintyre S. The Black report and beyond: what are the issues? Soc Sci Med 1997:44:723-45

28 Mackenbach JP, Kunst AE, Cavelaars AE, et al. Socioeconomic inequalities in morbidity and mortality in western Europe. The EU Working Group on Socioeconomic Inequalities in Health. Lancet 1997;349:1655-9.

29 Marmot $M$, Ryff CD, Bumpass LL, et al. Social inequalities in health: next questions and converging evidence. Soc Sci Med 1997;44:901-10.

30 Pan American Health Organization (PAHO). The search for equity: annual report of the director, 1995. Washington, DC: PAHO, 1996:ix.

31 Dahlgren G, Whitehead M. Policies and strategies to promote equity in health. Copenhagen: World Health Organization Regional Office for Europe, 1992.

32 Standing $\mathbf{H}$. Gender and equity in health sector reform programmes: a review. Health Policy Plan 1997;12:1-18

33 Murray CJL, Gakidou EE, Frenk J. Health inequalities and social group differences: what should we measure? Bull World Health Organ 1999:77:537-43.

34 Gakidou EE, Murray CJL, Frenk J. Defining and measuring health inequality. Bull World Health Organ 2000;78:42-54.

35 Murray CJL, Gakidou EE, Frenk J. Response to P Braveman et al. Bull World Health Organ 2000;78:234.

36 Braveman $\mathbf{P}$, Krieger $\mathrm{N}$, Lynch J. Health inequalities and social inequalities in health. Bull World Health Organ 2000;78:232-4.

37 Braveman P, Starfield B, Geiger HJ. The World Health Report 2000's 'health inequalities' approach removes equity from the agenda for public health monitoring and policy. BMU 2001;323:678-81.

38 Almeida C, Braveman P, Gold MR, et al. Methodologic concerns and recommendations on policy consequences of the World Health Report 2000. Lancet 2001;357:1692-7.

39 Beauchamp TL, Childress JF, eds. Principles of biomedical ethics. New York: Oxford University Press, 1994:326-59.

40 Rawls J. Justice as fairness. Philos Public Aff 1985;14:223-51

41 Daniels N, Kennedy BP, Kawachi I. Why justice is good for our health: the social determinants of health inequalities. Daedalus 1999;1 28:211-51

42 Feinberg J. Justice. In: Reich WT, ed. Encyclopedia of bioethics. New York: Macmillan, 1995:802-10.

43 World Health Organization. Constitution of the World Health Organization as adopted by the International Health Conference, New York 19-22 June, 1946; signed on 22 July 1946 by the representatives of 61 States (Official Records of the World Health Organization no 2).

44 Institute of Medicine, Committee for the Study of the Future of Public Health, Division of Health Care Services. The future of public health. Washington, DC: National Academy Press, 1988

45 Leon DA, Walt G, eds. Poverty, inequality and health: an international perspective. Oxford: Oxford University Press; 2001.

46 Amick BC, Levine S, Tarlov AR, et al, eds. Society and health. New York: Oxford University Press, 1995.

47 Auerbach JA, Krimgold BK, eds. Income, socioeconomic status, and health: exploring the relationships. Washington, DC: National Policy Association, 2001

48 Multiple authors. Health and wealth. Daedalus: Journal of the American Academy of Arts and Sciences 1994;123.

49 Berkman L, Kawachi I, eds. Social epidemiology. Oxford: Oxford University Press, 2000

50 Moon G Gillespie R, eds. Society and health: an introduction to social science for health professionals. London: Routledge, 1995.

51 Runciman WG, ed. Classes, status groups and parties. Weber: Selections in translation. Cambridge: Cambridge University Press, 1978:43-61.

52 Krieger N. A glossary for social epidemiology. J Epidemiol Community Health 2001;55:693-700.

53 Marmot MG, Davey Smith G, Stansfeld S, et al. Health inequalities among British civil servants: the Whitehall II study. Lancet $1991 ; 337: 1387-93$

54 Wilkinson RG. Socioeconomic determinants of health. Health inequalities: relative or absolute material standards? BM 1997;314:591-5.

55 United Nations Development Programme (UNDP). Human Development Report 1997. New York: Oxford University Press, 1997

56 Starfield B. Improving equity in health: a research agenda. Int J Health Serv 2001;31:545-66. 
57 Oliver A, Healy A, LeGrand J. Addressing health inequalities. Lancet 2002;360:565-7.

58 Ngwena C. The recognition of access to health care as a human right in South Africa: Is it enough? Health Hum Rights 2000;5:26-45.

59 Leary V. The right to health in international law. Health Hum Rights $1994 ; 1: 24-56$

60 United Nations Committee on Economic, Social and Cultural Rights. The right to the highest attainable standard of health: E/C.12/2000/4 CESCR General Comment 14. Geneva: UN, 2000.

61 Gruskin S, Tarantola D. Health and human rights. In: Detels R, Beaglehole R, eds. Oxford textbook on public health. New York: Oxford University Press, 2002:312-35.

62 Torres $M$. The human right to health, national courts and access to HIV/AIDS treatment: a case study from Venezuela. Chicago Journal of International Law 2002;3:105-14.

63 Giesen D. A right to health care: a comparative perspective. Health Matrix 1994;4:277-94.

64 Coomeraswamy R. Reinventing international law: women's rights as human rights in the international community. Edward A Smith Lecture. A publication of the Harvard Law School Human Rights Program, 1997: 1-14.

65 Sullivan D. Envisioning women's human rights: What was achieved in Beijing? China Rights Forum 1995;19:21
66 Abeyesekera S. Women's human rights, questions of equality and difference. The Hague: ISS Working Paper no 186, 1995.

67 Gillespie R, Gerhardt C. Social dimensions of sickness and disability. In Moon G, Gillespie R, eds. Society and health: an introduction to social science for health professionals. London: Routledge, 1995:79-93.

68 Abberly P. Disabled people and 'normality.' In: Swain J, Finkelstein V, French S, eds. Disabling barriers-enabling environments. London: Sage, 1993:107-15.

69 United Nations. UN world conference on human rights. Vienna: GA resolution number 48/121, 1993.

70 Mann JM, Gruskin S, Grodin MA, et al, eds. Health and human rights. New York: Rutledge, 1999.

71 World Health Organization. World Health Report 2000. Geneva: WHO, 2000:205

72 Alleyne GAO, Casas J, Castillo-Salgado C. Equality, equity: why bother? Bull World Health Organ 2000;78:76-7.

73 Wagstaff A. Poverty and health. Geneva: World Health Organization of Macroeconomics and Health, 2001

74 Mackenbach JP, Kunst AE. Measuring the magnitude of socioeconomic inequalities in health: an overview of available measures illustrated with two examples from Europe. Soc Sci Med 1997:44:757-71.

75 Wagstaff A, Paci P, van Doorslaer E. On the measurement of inequalities in health. Soc Sci Med 1991;33:545-57. 